\title{
Functionality Diagrams for Hybrid Mechanical Seals with Silicon Nitride Rings
}

\author{
João M. Carrapichano ${ }^{\dagger}$ \\ Mechanical Engineering Department, ISEC, 3040-228 Coimbra, Portugal \\ Filipe J. Oliveira and Rui F. Silva \\ Ceramics Engineering Department, CICECO, University of Aveiro, 3810-193 Aveiro, Portugal \\ José R. Gomes \\ Mechanical Engineering Department, CIICS, University of Minho, 4800-058 Guimarães, Portugal
}

\begin{abstract}
Ring-on-ring tribological experiments were performed with hybrid mechanical seals with silicon nitride $\left(\mathrm{Si}_{3} \mathbf{N}_{4}\right)$ rings. The $K \times P V$ product, where $K$ is the wear coefficient, $P$ the sealing pressure, and $V$ the linear speed, is proposed as a novel parameter to characterize the total working range of a mechanical seal system, with the advantage of directly indicating the thickness reduction for a certain time of service. The $K \times P V$ criterion is represented in a map form called "functionality diagram." The rotary $\mathrm{Si}_{3} \mathrm{~N}_{4}$ rings show the better behavior $(K \times P V=0.05 \mu \mathrm{m} /$ h) against $\mathrm{WC}-\mathrm{Co}$ mating faces.
\end{abstract}

\section{Introduction}

$\mathrm{M}$ ECHANICAL seals are safety components to avoid fluid losses or contaminations from transfers between neighboring chambers in machine elements. Leakage control is imperative when fluids, liquids, or gases, are toxic, corrosive, inflammable, explosive, and radioactive. Hence, these components are present in the most important industries (chemistry, alimentary, pharmaceutical, cellulose, textile, cryogenics, power energy, nuclear, automotive, gas refineries, etc.) and human activities (agriculture machinery, navy, transports, etc.). ${ }^{1,2}$

A mechanical seal part is formed by two rings, usually made of dissimilar materials: a rotary, primary, or dynamic ring, which is fixed to the shaft, and a static ring or counter-ring, mechanically linked to the machine stator. The sealing effect is guaranteed by the adding up of the pressure of a spring actuating on the dynamic ring, to the hydraulic one resulting from the working fluid. ${ }^{1,2}$ In liquid sealing, and if the mechanical seal faces are flat, the most common regime is boundary lubrication. In this condition, the volume of interfacial liquid film is limited and so is the hydrodynamic pressure to support the load, and solid contact takes place between the surfaces. Some wear is inevitable and careful material selection and surface finish requirements are crucial for minimizing friction and wear.

The $P V$ product ( $P$ is the effective pressure on the working faces and $V$ their respective linear speed) is the usual parameter for material's mechanical seal selection. All classes of materials have been used in the fabrication of these components, providing a wide range of applications depending on the required service condition. Among these, ceramics and ceramic-matrix composites possess an appropriate combination of high corro-

K.-H. Zum Gahr-contributing editor

Manuscript No. 20137. Received October 3, 2004; approved February 8, 2005. Supported by ADI, Portugal (VEDACERAM project 6443/POCTI 2.3).

${ }^{\dagger}$ Author to whom correspondence should be addressed. e-mail: joaomaia@isec.pt sion resistance, low wear, and low inertial mass. Silicon carbide, alumina, zirconia, and silicon nitride are the most common ceramics used as mating surfaces. ${ }^{2-4}$ The latter is an attractive choice because of its relatively high fracture toughness and low processing cost, compared with the other ceramics. ${ }^{5}$ Only a few works report on the tribological performance of $\mathrm{Si}_{3} \mathrm{~N}_{4}$-based seals. In gas turbine application, this ceramic, in monolithic form or reinforced by $\mathrm{BN}$ particles, showed a high oxidation resistance when exposed to the hot $\left(1400^{\circ} \mathrm{C}\right)$ combustion products, assuring a relatively low friction coefficient (0.09-0.11) in full sealing condition. ${ }^{6}$ The present authors, in a previous paper, ${ }^{5}$ described the wear mechanisms of self-mated $\mathrm{Si}_{3} \mathrm{~N}_{4}$ and $\mathrm{Si}_{3} \mathrm{~N}_{4}$ gray cast iron (GCI) systems and demonstrated that the dissimilar pair is the best combination, by preventing fluid leakage and providing a moderate wear coefficient $\left(K \approx 10^{-8} \mathrm{~mm}^{3} /\right.$ $\mathrm{N} / \mathrm{m})$.

In the present work, the tribological behavior of hybrid mechanical seals with $\mathrm{Si}_{3} \mathrm{~N}_{4}$ rings in planar contact against hardmetals and GCI is fully characterized. A new useful representation ("functionality diagram") for selection of a certain sealing system is proposed based on the product $K \times P V$, a measure of the seal ring thickness reduction for a certain time of service.

\section{Materials and Experiments}

Several materials were selected to produce rings for tribological characterization: (i) silicon nitride, $\mathrm{Si}_{3} \mathrm{~N}_{4}(\mathrm{SN})$; (ii) silicon nitride/carbide composites, $\mathrm{Si}_{3} \mathrm{~N}_{4} / 10 \mathrm{wt}^{\circ} \mathrm{SiC}$ (SN10SC) and $\mathrm{Si}_{3} \mathrm{~N}_{4} / 30 \mathrm{wt} \% \mathrm{SiC}$ (SN30SC); (iii) GCI BS grade 200 (GCI); and (iv) hardmetal ISO grade GD05, WC $/ 5 \mathrm{wt} \%$ Co (WC). Details on the composition, sintering procedure, and mechanical properties of the $\mathrm{Si}_{3} \mathrm{~N}_{4}$-based ceramic materials are described elsewhere. ${ }^{5}$ Before testing, the working surfaces were polished, giving rise to initial roughness values $\left(R_{\mathrm{a}}\right)$ presented in Table I and to the typical microstructures shown in Fig. 1.

Ring-on-ring tribological experiments were carried out in a rotary tribometer (TE-92, Plint \& Partners, UK). Complex load application and speed variations are possible through a microprocessor that controls the angular speed in the range $0-3000 \mathrm{rpm}$ and the load in the range 0-2000 N. The tests were carried out in planar contact configuration (ASTM D3702-94), simulating a mechanical sealing process. The dimensions of the upper and lower rings for the tribological testing are, respectively, 4333-6 and 46-31-6 (external diameter-internal diameter thickness in millimeter). The tests were conducted at room temperature in minimal $P V$ conditions (effective pressure $\times$ linear speed) that assured effective sealing under an internal pressure of $2 \times 10^{5} \mathrm{~Pa}$ of a mixture of $20 \mathrm{vol} \%$ of hydrogen peroxide in deionized 
Table I. $\quad P V$ Product $\left(P\right.$-Effective Pressure; $V$-Linear Speed), Friction $(f)$ and Wear $(K)$ Coefficients, and Roughness $\left(R_{\mathrm{a}}\right)$ Values for the Distinct Ring-on-Ring Tested Pairs

\begin{tabular}{|c|c|c|c|c|c|c|c|c|c|c|c|}
\hline \multirow[b]{3}{*}{ Tested pair } & \multirow[b]{3}{*}{$P(\mathrm{MPa})$} & \multirow[b]{3}{*}{$V(\mathrm{~m} / \mathrm{s})$} & \multirow[b]{3}{*}{$f$} & \multicolumn{2}{|c|}{$K\left(\mathrm{~mm}^{3} / \mathrm{N} / \mathrm{m}\right)$} & \multicolumn{2}{|c|}{$K \times P V(\mu \mathrm{m} / \mathrm{h})$} & \multicolumn{4}{|c|}{$R_{\mathrm{a}}(\mu \mathrm{m})$} \\
\hline & & & & \multirow[b]{2}{*}{ Upper ring } & \multirow[b]{2}{*}{ Lower ring } & \multirow[b]{2}{*}{ Upper ring } & \multirow[b]{2}{*}{ Lower ring } & \multicolumn{2}{|c|}{ Upper ring } & \multicolumn{2}{|c|}{ Lower ring } \\
\hline & & & & & & & & Initial & Final & Initial & Final \\
\hline $\mathrm{SN} / \mathrm{GCI}$ & 0.170 & 4.10 & 0.15 & $4.2 \times 10^{-8}$ & $1.3 \times 10^{-7}$ & 0.11 & 0.33 & 0.067 & 0.082 & 2.194 & 0.258 \\
\hline SN30SC/GCI & 0.146 & 4.26 & 0.15 & $5.9 \times 10^{-6}$ & $5.3 \times 10^{-7}$ & 13.21 & 1.18 & 0.114 & 0.132 & 2.194 & 2.000 \\
\hline $\mathrm{GCI} / \mathrm{GCI}$ & 0.171 & 4.35 & 0.22 & $5.3 \times 10^{-7}$ & $5.6 \times 10^{-7}$ & 1.42 & 1.50 & 2.194 & 1.121 & 2.194 & 0.841 \\
\hline $\mathrm{SN} / \mathrm{WC}$ & 1.247 & 4.10 & 0.03 & $7.7 \times 10^{-8}$ & $9.8 \times 10^{-8}$ & 1.42 & 1.80 & 0.067 & 0.075 & 0.007 & 0.112 \\
\hline SN10SC/WC & 1.250 & 4.14 & 0.02 & $2.9 \times 10^{-9}$ & $5.0 \times 10^{-8}$ & 0.05 & 0.93 & 0.100 & 0.095 & 0.007 & 0.205 \\
\hline $\mathrm{WC} / \mathrm{WC}$ & 1.243 & 4.35 & 0.03 & $2.1 \times 10^{-8}$ & $3.5 \times 10^{-8}$ & 0.41 & 0.68 & 0.007 & 0.030 & 0.007 & 0.026 \\
\hline
\end{tabular}

$\mathrm{SN}, \mathrm{Si}_{3} \mathrm{~N}_{4}$; GCI, gray cast iron; $\mathrm{SN} 10 \mathrm{SC}, \mathrm{Si}_{3} \mathrm{~N}_{4} / 10 \mathrm{wt} \% \mathrm{SiC}$; SN30SC, $\mathrm{Si}_{3} \mathrm{~N}_{4} / 30 \mathrm{wt} \% \mathrm{SiC}$; WC, WC sintered with $5 \mathrm{wt} \% \mathrm{Co}$.

water. This fluid was chosen to simulate sealing under severe oxidation conditions. The adopted linear speed was almost constant $(V \approx 4 \mathrm{~m} / \mathrm{s})$, while the sealing effective pressure depended on the opponent ring material $(P \approx 0.2$ and $P \approx 1.3 \mathrm{MPa}$ for GCI and WC, respectively), as detailed in Table I. A load cell continuously measured the friction torque of the tribosystem from which the respective average friction coefficient $(f)$ was calculated considering several steps (a minimum of 4) within a total sliding distance between 66 and $890 \mathrm{~km}$, depending on the wear resistance of the sliding pair. The corresponding average wear coefficient $(K)$ was evaluated taking the ratio between the volume loss and the effective load $\times$ sliding distance product, the volume loss being assessed by weighing the samples. Both tribological parameters were appraised in steady-state conditions after a running-in period. The worn surfaces of the rings were analyzed by scanning electron microscopy with chemical analysis (SEM/EDS), and the dominant wear mechanisms were identified.

\section{Tribological Performance}

\section{(1) Ceramic Rings}

Table I presents the friction and wear coefficients of the tested pairs, together with the initial and final surface roughness of the rings. Regarding the tribological parameters, it must be pointed out that when WC parts are involved, $f$ is approximately onetenth of the values calculated for GCI contacts and $K$ is almost one order of magnitude lower.

The comparison between the surface roughness of the ceramic rings before and after testing (Table I) shows no significant
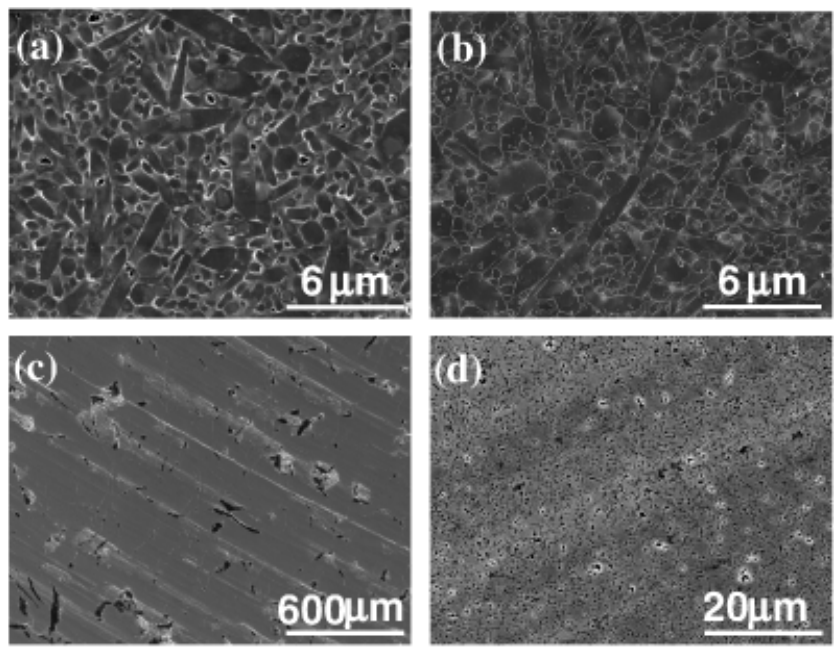

Fig. 1. Microstructures of ring materials before tribological testing (scanning electron microscopy images): (a) monolithic silicon nitride $\left(\mathrm{Si}_{3} \mathrm{~N}_{4}\right)\left(\mathrm{CF}_{4}\right.$ plasma etched); (b) $\mathrm{Si}_{3} \mathrm{~N}_{4} / 10 \mathrm{wt} \% \mathrm{SiC}$ composite $\left(\mathrm{CF}_{4}\right.$ plasma etched); (c) gray cast iron; (d) WC/5 wt\% Co. changes on the surface topography. The worn surfaces of monolithic $\mathrm{Si}_{3} \mathrm{~N}_{4}$ are very smooth after sliding against both GCI and $\mathrm{WC} / \mathrm{Co}$ rings (Figs. 2(a) and (c)). A general feature is the extensive covering of $\mathrm{Si}_{3} \mathrm{~N}_{4}$ with an oxygen-rich layer, as detected by EDS analysis. This is explained by the well-established tribochemical mechanism of amorphous silica formation after $\mathrm{Si}_{3} \mathrm{~N}_{4}$ and $\mathrm{SiC}$ hydration. ${ }^{7,8}$ This layer afforded third-body protection to the ceramic ring surfaces, keeping the wear coefficient values in the acceptable range of $10^{-9}-10^{-8} \mathrm{~mm}^{3} / \mathrm{N} / \mathrm{m}$ (Table I). The thickness of this tribolayer is higher in the inner contact area where the fluid has access, as previously discussed. ${ }^{5}$ A remarkable value of $2.9 \times 10^{-9} \mathrm{~mm}^{3} / \mathrm{N} / \mathrm{m}$ is presented by the SN10SC ring when sliding against the $\mathrm{WC} / \mathrm{Co}$ counterpart. This ceramic composite presents better mechanical properties $\left(H_{\mathrm{V}}=13.4\right.$ $\mathrm{GPa}$ and $\left.K_{\mathrm{I} c}=6.3 \mathrm{MPa} \cdot \mathrm{m}^{1 / 2}\right)$ than the monolithic $\mathrm{Si}_{3} \mathrm{~N}_{4}$ material $\left(H_{\mathrm{V}}=12.1 \mathrm{GPa}\right.$ and $\left.K_{\mathrm{I} c}=6.0 \mathrm{MPa} \cdot \mathrm{m}^{1 / 2}\right)$ and thus a higher wear resistance. The addition of a great amount of $\mathrm{SiC}$ particles to the $\mathrm{Si}_{3} \mathrm{~N}_{4}$ matrix (SN30SC) led to a detrimental tribological response. A representative morphology of the SN30SC worn surface is given in Fig. 2(b). Here, the silica smooth layer continuity is interrupted by material detachments, namely $\mathrm{SiC}$ particle debonding and pullout, as a consequence of the lack of matrix/dispersoid interfacial mechanical resistance. ${ }^{9}$ This results in a relatively high surface roughness $(>0.1 \mu \mathrm{m})$, even for the initial polishing state, as well as in a two order of magnitude higher wear coefficient than for SN/GCI contacts, reaching $10^{-6} \mathrm{~mm}^{3} / \mathrm{N} / \mathrm{m}$ (Table I).

\section{(2) GCI Rings}

The mating GCI surfaces of the hybrid systems with $\mathrm{Si}_{3} \mathrm{~N}_{4}$ rings (Fig. 3(a)) are also covered by broad oxidized layers from metal oxidation after the aqueous media corrosive action and transferred silica from the ceramic. However, this tribolayer is not so effective in protecting the metal alloy than in the ceramic counterface, because the graphite flakes tend to be removed, leading to large cavities at the contact surface. The graphite brittleness also explains the high initial surface roughness of GCI by polishing $\left(R_{\mathrm{a}}=2.194 \mu \mathrm{m}\right.$ in Table I). The GCI wear mechanism of the SN/GCI tribopair starts with a low-scale abrasion by loose ceramic particles, ${ }^{10}$ which explains the notable decrease of $R_{\mathrm{a}}$, followed by the mentioned tribooxidation and graphite pull-out effects. The relatively low $K$ and $R_{\mathrm{a}}$ values are in agreement with those of the ceramic counterpart (Table I). For the tested GCI ring against the $\mathrm{Si}_{3} \mathrm{~N}_{4} / 30 \mathrm{wt} \% \mathrm{SiC}$ composite, the final $R_{\mathrm{a}}$ value is very high like in the as-polished state, meaning that the abovereferred microscale abrasion was not effective. In fact, the ceramic composite had the highest wear rate observed in the present set of distinct triboelements, as reported above, giving rise to a rough surface that causes net abrasive grooves and assists in graphite removal at the GCI counterface (Fig. 3(a)). The $K$ value of the GCI ring of the SN30SC/GCI system is therefore higher than the corresponding $K$ of the $\mathrm{SN} / \mathrm{GCI}$ pair (Table I). 

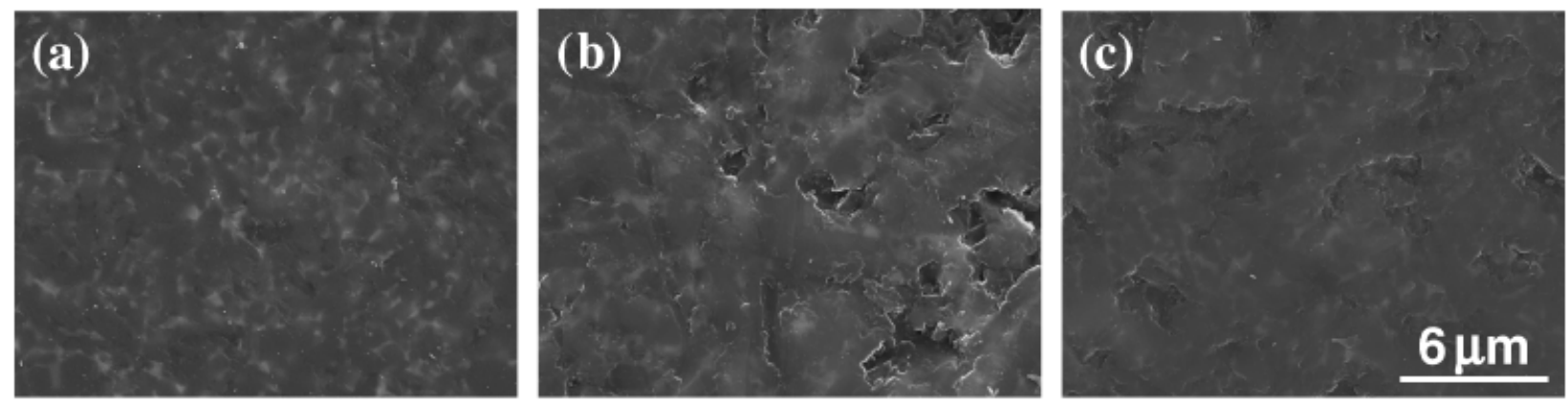

Fig. 2. Scanning electron microscopy micrographs of the ceramic worn surfaces from the tested pairs: (a) silicon nitride $\left(\mathrm{Si}_{3} \mathrm{~N}_{4}\right)$ against gray cast iron; (b) $\mathrm{Si}_{3} \mathrm{~N}_{4} / 30 \mathrm{wt} \% \mathrm{SiC}$ against gray cast iron; (c) $\mathrm{Si}_{3} \mathrm{~N}_{4}$ against $\mathrm{WC} / 5 \mathrm{wt} \% \mathrm{Co}$.

Self-mated GCI ring-on-ring experiments were also performed to compare the tribological response of the metallic ring with that of the hybrid systems with ceramic parts. Figure 3(b) shows the main features of the worn GCI morphology: (i) polished regions; (ii) graphite flake cavities; and (iii) adherent agglomerates of oxides aligned along the sliding direction. Unlike the SN/GCI system, polishing action from abrasive loose particles and tribolayer protection by silica is absent, resulting in a higher $R_{\mathrm{a}}$ final value (Table I), although lower than for the case of the deleterious contact with the $\mathrm{Si}_{3} \mathrm{~N}_{4} / 30 \mathrm{wt} \% \mathrm{SiC}$ ring.

\section{(3) Tungsten Carbide Rings}

The surface morphology of the mating $\mathrm{WC} / 5 \mathrm{wt} \%$ Co surfaces tested against the $\mathrm{SN}$ or the SN10SC ceramic rings is characterized by uniform oxidation (dark areas), although alternated with scratched regions coming from $\mathrm{Si}_{3} \mathrm{~N}_{4}$ two- and three-body abrasive action (Fig. 3(c)). According to this, the $R_{\mathrm{a}}$ value of the WC ring significantly increases from 0.007 to 0.112 or $0.205 \mu \mathrm{m}$ (Table I). On the contrary, in self-mated WC/Co experiments, the hard metal surfaces almost preserve the initial polished level, the $R_{\mathrm{a}}$ value slightly increasing to $0.026 \mu \mathrm{m}$ (Table I). Extensive oxygen-rich tribofilms spread along the sliding direction (dark areas in Fig. 3(d)) protecting the WC operating ring surface.

\section{Functionality $K$ Versus $P V$ Diagram}

The major operating parameters of mechanical seals are the effective pressure $(P)$ at the contact surface and the linear speed $(V)$, the product of these assuming a particular practical rele- vance because the minimum $P V$ value corresponds to the onset of the sealing condition and the maximum value is an indication of their lifetime limit. The wear coefficient $(K)$ of a mechanical seal is related to this product by the following equation:

$$
K=\frac{W_{V}}{(P V) A t}
$$

where $W_{V}$ is the wear volume for a given time $(t)$ and $A$ is the open hydraulic area. Thus, the $K \times P V$ product is a measure of the surface loss of the sealing system for a given time of service and it can be expressed in convenient units of $\mu \mathrm{m} / \mathrm{h}$ for design purposes. From Eq. (1), the logarithmic representation $\ln (K)$ versus $\ln (P V)$ is a suitable way to rank each mechanical seal combination. This is plotted in Fig. 4 for the overall set of upper/lower ring values presented in Table I. If an acceptable ring thickness reduction is assumed, the lifetime of a system increases with decreasing origin intercepts of -1 slope straight lines passing through each pair of values. Moreover, the best systems are those that present the lowest $P V$ product for effective sealing, i.e. with leftward tendency. The combination of minimal wear and least $P V$ sealing condition is sketched in Fig. 4 by a resultant arrow pointing to the bottom left corner of the graph. This representation, here called the "functionality diagram," allows the selection of a mechanical seal system in a worthwhile form.

Figure 4 shows that the system with the better performance with minimal sealing onset conditions is the hybrid pair SN/GCI that presents a $K \times P V$ value of $0.11 \mu \mathrm{m} / \mathrm{h}$ for the ceramic ring and $0.33 \mu \mathrm{m} / \mathrm{h}$ for the metallic counterpart. On the contrary, the worst combination put in evidence by the functionality diagram
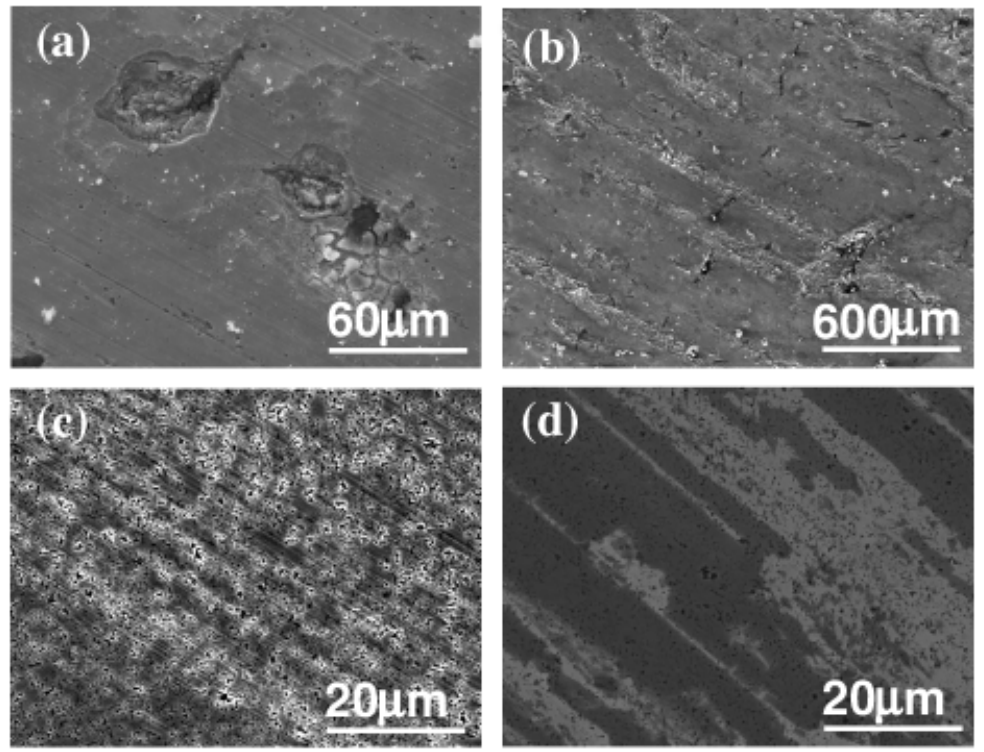

Fig. 3. Scanning electron microscopy micrographs of the worn surfaces of gray cast iron and $\mathrm{WC}$ from the tested pairs: (a) $\mathrm{Si}_{3} \mathrm{~N}_{4} / 30 \mathrm{wt} \% \mathrm{SiC}$ against gray cast iron; (b) self-mated gray cast iron; (c) $\mathrm{Si}_{3} \mathrm{~N}_{4}$ against $\mathrm{WC} / 5 \mathrm{wt} \% \mathrm{Co}$; (d) self-mated $\mathrm{WC} / 5 \mathrm{wt} \%$ Co. 


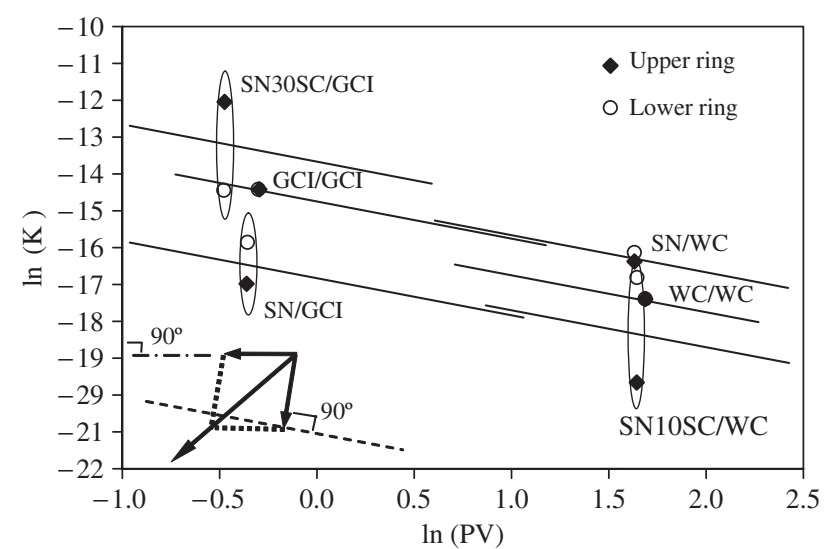

Fig. 4. Functionality diagram of the different tested tribopairs.

corresponds to the SN30SC/GCI system. This is in accordance to the poor tribological performance of this pair as described in the previous section. In spite of the fact that the lowest $K \times P V$ value found in the overall set of rings is the one corresponding to the SN10SC material against $\mathrm{WC}(0.05 \mu \mathrm{m} / \mathrm{h})$, the $P V$ condition for full sealing with WC rings is tenfold that against GCI rings. The lower hardness of GCI relative to WC and its lower oxidation resistance lead to a faster sealing of the opponent rings because of larger amounts of surface oxides and an easier surface polishing/accommodation. Another disadvantage of the sealing systems with the WC conventional material is its high specific weight, which can dissuade its application in large-diameter rotary rings.

\section{Conclusions}

Hybrid mechanical seals made of $\mathrm{Si}_{3} \mathrm{~N}_{4}$-based rings combined with GCI or hardmetal (WC-Co) ones proved to be adequate for sealing of aqueous solutions. Outstanding values of $K=2.9 \times 10^{-9} \mathrm{~mm}^{3} / \mathrm{N} / \mathrm{m}$ for the wear coefficient and $f=0.02$ for the friction coefficient result when a $\mathrm{Si}_{3} \mathrm{~N}_{4}-10 \mathrm{wt} \% \mathrm{SiC}$ composite ring is used against a WC-Co counterpart. In $\mathrm{Si}_{3} \mathrm{~N}_{4}$ / GCI systems, $K$ is almost one order of magnitude higher and $f$ is approximately tenfold the above value. In both kinds of hybrid systems, the ceramic composite ring surfaces are protected by an extensive oxygen-rich layer, mainly amorphous silica, from $\mathrm{Si}_{3} \mathrm{~N}_{4}$ and $\mathrm{SiC}$ hydration.

The $K \times P V$ product is proposed to be a convenient measure of the surface loss of the sealing system for designing purposes, as it is expressed in convenient units of $\mu \mathrm{m} / \mathrm{h}$. The mechanical seal system with better performance is the SN/GCI with a $K \times P V$ value of $0.11 \mu \mathrm{m} / \mathrm{h}$ for the ceramic ring and $0.33 \mu \mathrm{m} /$ $\mathrm{h}$ for the metallic counterpart. However, considering only the ceramic ring, the best results $(K \times P V=0.05 \mu \mathrm{m} / \mathrm{h})$ are obtained against the WC ring. The logarithmic representation $\ln (K)$ versus $\ln (P V)$, here called the "functionality diagram," is a suitable way to rank the performance of each mechanical seal combination.

\section{References}

${ }^{1}$ M. J. Neale, Tribology Handbook. Butterworth-Heinemann, Stoneham, MA, 1997.

${ }^{2}$ M. Brown, Seals and Sealing Handbook. Elsevier Advanced Technology, Amsterdam, 1995

${ }^{3}$ G. A. Jones, "On the Tribological Behaviour of Mechanical Seals Face Materials in Dry Line Contact. Part II. Bulk Ceramics, Diamond and Diamond-Like Carbon Films," Wear, 256, 433-55 (2004).

${ }^{4}$ R. Divakar, "Ceramics in Mechanical Face Seal Applications," pp. 357-81 in Friction and Wear of Ceramics, Edited by S. Jahanmir. Marcel Dekker Inc., New York, 1997.

${ }_{5}^{5}$ J. M. Carrapichano, J. R. Gomes, F. J. Oliveira, and R. F. Silva, " $\mathrm{Si}_{3} \mathrm{~N}_{4}$ and $\mathrm{Si}_{3} \mathrm{~N}_{4} / \mathrm{SiC}$ Composite Rings for Dynamic Sealing of Circulating Fluids," Wear, 255, 695-8 (2003).

${ }^{6}$ V. V. Vikulin, I. Yu. Kelina, and N. I. Ershova, "Advanced Materials for HighTemperature Friction Units"; Proceedings of the Second World Tribology Congress, Austria, 2001, Pub. CD-ROM.

${ }^{7}$ M. Chen, K. Kato, and K. Adachi, "Friction and Wear of Self-Mated SiC and $\mathrm{Si}_{3} \mathrm{~N}_{4}$ Sliding in Water," Wear, 250, 246-55 (2001).

${ }^{8}$ T. Saito, T. Hosoe, and F. Honda, "Chemical Wear of Sintered $\mathrm{Si}_{3} \mathrm{~N}_{4}, \mathrm{hBN}$ and $\mathrm{Si}_{3} \mathrm{~N}_{4}-\mathrm{hBN}$ Composites by Water Lubrication," Wear, 247, 223-30 (2001).

${ }^{9}$ J. R. Gomes, M. I. Osendi, P. Miranzo, F. J. Oliveira, and R. F. Silva, "Tribological Characteristics of Self-Mated Couples of $\mathrm{Si}_{3} \mathrm{~N}_{4}-\mathrm{SiC}$ Composites in the Range $22^{\circ} \mathrm{C}-700^{\circ} \mathrm{C}, "$ Wear, 233-235, 222-8 (1999).

${ }^{10}$ J. R. Gomes, A. S. Miranda, R. F. Silva, and J. M. Vieira, "Tribo-Oxidational Effects on Friction and Wear Behavior of Silicon Nitride/Tool Steel and Silicon Nitride/Gray Cast Iron Contacts," J. Am. Ceram. Soc., 82 [4] 953-60 (1999). 